\title{
Review on Optimising Solar PV Efficiency by Using Tracking and Cooling System
}

\author{
Anil Khatri \\ M. Tech. scholar \\ Sagar Institute of Research \& Technology \\ Bhopal, India \\ anilkhatri.mech@gmail.com
}

\author{
Prof. Nitin Tenguria \\ Assistant Professor \\ Sagar Institute of Research \& Technology \\ Bhopal, India \\ tengurianitin@gmail.com
}

\begin{abstract}
The increasing energy demand, continuous drawback of the existing sources of fossil fuels and increasing concern about environmental pollution pushed researchers to explore new technologies for the production of electricity from clean sources, renewable such as solar, wind etc. Solar energy is the oldest primary source of energy. It is a source of clean, renewable energy and it is found in abundance in every part of the world. Using solar energy is possible to convert it into mechanical energy or electricity with adequate efficiency. In this paper of the present of principal of solar cell and the temperature effect. And the Information about the quality and amount of solar energy available at a specific location is of prime importance for the development of a solar energy system. However, the amount of electricity that is obtained is directly proportional to the intensity of sunlight falling on the photovoltaic panel.
\end{abstract}

Keyword - photovoltaic cell, panel, solar panel.

\section{INTRODUCTION}

Solar tracking negotiates compound sun angles, complex field geometries, and mechanical systems in pursuit of optimal energy generation.[1,2] Solar tracking also results in an optimally oriented shading surface, but in order to cooptimize the shading of target areas (e.g. work surfaces, windows, playgrounds) it is necessary to consider both the geometry toward the sun and also the geometry underneath the shade.[3,4] The novel implementation of shades that also implement energy harvesting though photovoltaic panels raises the question of how to negotiate both shading and generation most effectively.[5,6] When a fixed surface is the desired shading target, the geometry of rotation must extend the shading panel out into an arc whereby the panel remains both normal to the sun and also stays on the vector from the target surface to the sun. This cannot be achieved with conventional 2- axis gearboxes or gimbal system operation.[7,8] We have approached this issue from a geometric perspective considering curved PV surfaces, which are underrepresented in the literature.[9,10] The ever changing sun angles, orbit eccentricities, and shading constraints parameterize our novel solar tracking and shading methodology.[11,12] The goal of this research is to investigate optimal positioning/tracking through simulation of a roof or awning geometry and curvature for both PV energy generation and shading.[13,15] The simulation maximizes the normal orientation of solar panels to the incoming solar rays to maximize the power factor, while also fixing a defined shadow form to maintain shading on a specific target area. 


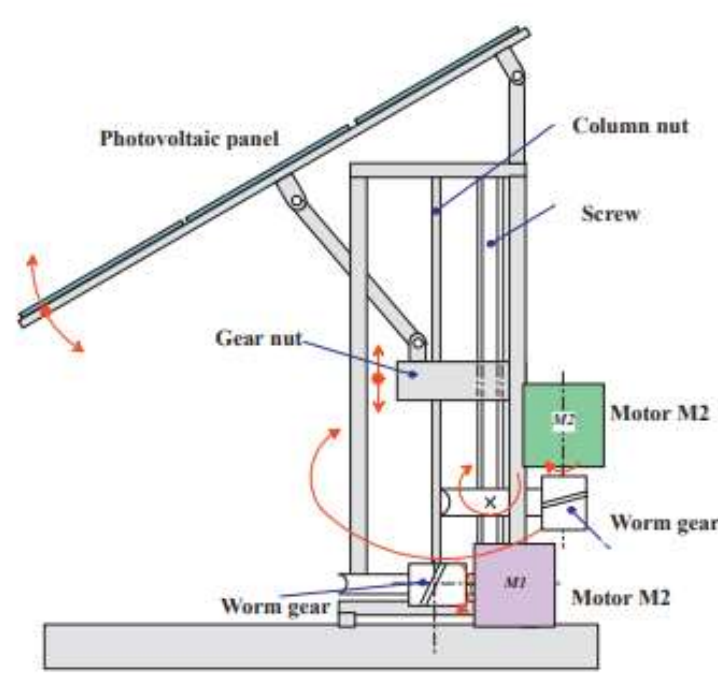

Figure 1 the mechanical structure for the positioning of the solar panels.

\section{LITERATURE REVIEW}

Mohamed Sabry et al [16]Active cooling is essential for solar cells operating under high optical concentration ratios. A system comprises four solar cells that are in thermal contact on top of a copper tube is proposed. Water is flowing inside the tube in order to reduce solar cells temperature for increasing their performance. Computational Fluid Dynamics (CFD) simulation of such system has been performed in order to investigate the effect of water flow rate, tube internal diameter, and convective heat transfer coefficient on the temperature of the solar cells. It is found that increasing convective heat transfer coefficient has a significant effect on reducing solar cells temperatures operating at low flow rates and high optical concentration ratios. Also, a further increase of water flow rate has no effect on reducing cells temperatures.

Manxuan Xiao et al. [17] Concentrated Photovoltaics (CPV) technology, as an energy saving method which can directly generate electricity from the Sun, has attracted an ever-increasing attention with the deepening worldwide energy crisis. However, operating temperature is one of the main concerns that affect the CPV system. Excess cell temperature causes electrical conversion efficiency loss and cell lifespan decrease. Thus, reasonable cooling methods should decrease the operating temperature and balance the flare inhomogeneity. They also need to display high reliability, low power consumption, and convenient installation. This paper presented the architectural, commercial, and industrial usage of CPV system, reviewed the recent research developments of different cooling techniques of CPV systems during last few years, including the spectral beam splitting technology, cogeneration power technology, commonly used and promising cooling techniques, active and passive cooling methods. It also analysed the design considerations of the cooling methods in CPV systems, introduced the classification and basic working principles and provided a thorough compilation of different cooling techniques with their advantages, current research limitations, challenges, and possible further research directions. The aim of this work is to find the research gap and recommend feasible research direction of cooling technologies for CPV systems.

Mohamed Sabry et al. [18] Solar energy is a good solution for energy-deficiency problems, especially in regions such as rural areas in the Middle East that have not been electrified yet or are under electrification. In this paper, with the aid of a Computational Fluid Dynamics simulation, we propose a system that comprises a trough solar concentrator and a pipe-with flowing waterthat is set in the concentrator focus. The aim of this work is to investigate the feasibility of generating steam from such a system as well as analyzing the generated steam quantitatively and qualitatively. Effects of variation of solar radiation intensity, ambient temperature, and water flow rate and pipe diameter on the quantity and quality of the generated steam have been investigated.

B.Suchithaet al. [19]in this paper I have attempted to utilize the solar power for operation of robot for surveillance with an intelligent feedback. As powering the robots for surveillance is difficult this project provides a solar powered mobile microcontroller based surveillance platform which is an amicable solution to the problem. The project involves a PIC microcontroller, digital compass, H-bridge drivers and a automatic solar tracker setup. The functioning of the solar tracking system is independent of the robot movement.

Meghana Sharma et al.[20]This paper isabout follow the sunlight direction across the sky by using a DC gear motor, the AT89S52 microcontroller controlthe movement of gear motor by this the solar panel will change their position, solar panel detects the sunlightusing photocells. The objective is to design and implement an 
automatic solar-tracking mechanism usingembedded system design with minimum cost and reliable structure.

David Appleyard et al. [21]this paper deals with the development of fully automated environment sensitive solar tracking system to maximize solar energy harvesting economically and efficiently. It is controlled by microcontroller with necessary interface. Limit switches are used to bring back the panel to morning position after each day without human interference.

P. Hatfield et al. [22] this paper presents the extremely low cost and robust dual axis tracking system that positions solar panel to receive maximum solar energy. Rotation around one axis is automatic and done daily to track the sun while second axis is used for manual adjustment against seasonal variation in the sun path. Database for position of the sun at any point of time from any location on earth is available online.

K. Sopian et al. [23] this paper presents theoretical and experimental analysis of double pass solar air collector with and without porous material. A mathematical model has been developed based on volumetric heat transfer coefficient. Effects of various parameters on the thermal performance and pressure drop characteristics have been discussed.

J. Prakash et al. [24]this paper presents a performance evaluation of flat plate solar $\mathrm{PV} / \mathrm{T}$ collector and comparing its performance with the solar PV system.Design of solar $\mathrm{PV} / \mathrm{T}$ system aims to reduce the operating temperature of PV modules and to keep the electrical efficiency at sufficient level. Photovoltaic systems are classified according to their applications.

T. Bergene et al. [25] The paper presents the simulation and analysis of an hybrid PV/Thermal solar collector, a combination of photovoltaic (PV) and solar thermal systems for the simultaneous production of electricity and heat from one integrated component.

T. Fujisawa et al. [26] this paper deals with the development of fully automated environment sensitive solar tracking system to maximize solar energy harvesting economically and efficiently. It is controlled by microcontroller with necessary interface. Limit switches are used to bring back the panel to morning position after each day without human interference.

www.ijoscience.com
B. Norton et al. [28] This paper presented the architectural, commercial, and industrial usage of CPV system, reviewed the recent research developments of different cooling techniques of CPV systems during last few years, including the spectral beam splitting technology, cogeneration power technology, commonly used and promising cooling techniques, active and passive cooling methods. It also analysed the design considerations of the cooling methods in CPV systems, introduced the classification and basic working principles and provided a thorough compilation of different cooling techniques with their advantages, current research limitations, challenges, and possible further research directions. The aim of this work is to find the research gap and recommend feasible research direction of cooling technologies for CPV systems.

G. Rockendorf et al. [29] this paper are the two different principles of thermoelectric cogeneration solar collectors have been realized and investigated. Concerning the first principle, the thermoelectric collector (TEC) delivers electricity indirectly by first producing heat and subsequently generating electricity by means of a thermoelectric generator. Concerning the second principle, the photovoltaic-hybrid collector (PVHC) uses photovoltaic cells, which are cooled by a liquid heattransfer medium. The characteristics of both collector types are described. Simulation modules have been developed and implemented in TRNSYS 14.1 (1994), in order to simulate their behaviour in typical domestic hotwater systems.

M. W. Davis et al. [30] This paper presents a technique to compute the operating temperature of cells within building integrated photovoltaic modules using a onedimensional steady state heat transfer model. The resulting predictions are compared to measured BIPV cell temperatures for two single crystalline BIPV panels. One panel is installed with thermal insulation attached to its rear surface. The second panel is installed without thermal insulation. Finally, the results are compared to predictions using the nominal operating cell temperature (NOCT) technique.

\section{III.PRINCIPAL OF SOLAR CELL}

Solar cells are made up of semiconducting materials, such as silicon, which are doped with different impurities. $[26,27]$ This produces unequal distribution of free electrons (n-type) on one side of junction and excess of 
holes (p-type) on other side of junction. Solar light has photons which hit the solar panel and excite the loosely bound electrons which are designed to move only in one direction in solar cells and thus electron-hole pairs are created in respective junctions and electricity is obtained in external circuit.[29,30] Whatever the size is, a typical solar cell produces $0.5-0.6$ volt DC under no load and open circuit condition. The current and voltage (power) ratting of a PV cell mainly depends on its efficiency, size (surface area) and is proportional to the intensity of light striking the surface of cell. For example, under peak sunlight conditions, a typical commercial PV panel of surface area $160 \mathrm{~cm}-2$ (25 inch-2) will produce 2 watts peak power.[31,32] If the intensity is 60 percent of peak it will produce about 1.2 watts. So intensity adds a lot to efficiency. Extensive research shows that output of a PV cell can be increased by two methods: fabrications and passive devices.[34,35] Passive devices are used widely to enhance the efficiency as fabrication is expensive one.

\section{IV.EFFECT OF IRRADIANCE}

Efficiency of solar cell is greatly affected by the amount of solar irradiance. It is one of the most dynamic factors which change the solar array performance $[36,38]$.

It is measure of amount of solar radiation from the sun striking on specific surface. It is commonly expressed in watts per square meter $(\mathrm{W} / \mathrm{m} 2)$. Under ideal conditions a solar panel should receive an irradiance of $1000 \mathrm{~W} / \mathrm{m} 2$ but unfortunately this is not true in most environments. Irradiance depends on geographical position, angle of sun to solar panel and amount of energy wasted by reflection from dust particles or from fog or clouds.[39,40] Therefore change of irradiance means change of output performance of solar panel.

\section{TEMPERATURE EFFECT}

Conducting materials consist of free electrons and some electrons are held tightly by the nucleus of atoms. When irradiance increases, more packets of photons strike the panel and this energy is absorbed by the atoms and electrons and they collide with each other emitting more electrons from the atoms and thus raising the temperature. Increase in temperature leads to increase in resistance to the flow of current. Efficiency is also dependent on temperature.[41,42] At high temperature output performance of solar panel reduces as compared to a lower temperature.

\section{VI.CONCLUSION}

Solar-tracking method design and implementation for experimental sun follower platforms. The presented control algorithm commands the movement of a photovoltaic module in order to follow the sun's radiation and to maximize the obtained solar energy. The implementation technique will reduce the costs of tracking method and makes it a cost-effective technology.

\section{REFERENCES}

[1] M. Despotovic, and V. Nedic, "Comparison of optimum tilt angles of solar collector determined at yearly, seasonal and monthly levels", Energy Conversion and Management, vol. 97, pp.121$131,2015$.

[2] H. Mousazadeh, A. Keyhani, A. Javadi, H. Mobli, K. Abrinia, and A. Sharifi "A review of principle and sun-tracking methods for maximizing solar systems output", Renewable and Sustainable Energy Reviews, vol. 13, pp. 1800-1818, 2009.

[3] R. C. Neville," Solar energy collector orientation and tracking mode", Solar Energy, vol. 20, pp. 7-11, 1978.

[4] N. A. Kelly, and T. L. Gibson, "Improved photovoltaic energy output for cloudy conditions with a solar tracking system", Solar Energy, vol. 83, pp. 2092-2102, 2009.

[5] N. A. Kelly, and T. L. Gibson, "Increasing the solar photovoltaic energy capture on sunny and cloudy days", Solar Energy, vol. 85, pp. 111-125, 2011.

[6] R. Marquez, H. T. C. Pedro, and C. F. M. Coimbra, "Hybrid solar forecasting method uses satellite imaging and ground telemetry as inputs to ANNs". Solar Energy, vol. 92, pp. 176-188, 2013.

[7] R. Marquez, and C. F. M. Coimbra, "Intra-Hour DNI forecasting based on cloud tracking image analysis". Solar Energy, vol. 91, pp. 327-336.

[8] C. N. Long, J. M. Sabburg, J. Calbo, and D. Pagés, "Retrieving cloud characteristics from ground-based daytime color all-sky images", J. Atmos. Ocean. Tech., vol. 23, pp. 633-652, 2006.

[9] A. Heinle, A. Macke, and A. Srivastav, "Automatic cloud classification of whole sky images", Atmos. Meas. Tech., vol. 3, pp. 557-567, doi:10.5194/amt-3-557-2010, 2010.

[10] Q. Li, W. Lu, and J. Yang, "A hybrid thresholding algorithm for cloud detection on ground-based color images", J. Atmos. Ocean. Tech., vol. 28, pp. 1286-1296, 2011.

[11] E. H. Mamdani, and S. Assilian, "An experiment in linguistic synthesis with a fuzzy logic controller", Int. J. Man-Machine Studies, vol. 7, pp. 1- 13,1975.

[12] T. Takagi, and M. Sugeno, "Fuzzy identification of systems and its applications to modeling and control", IEEE Trans Syst Man Cybern, vol. 15, pp. 116-32, 1985

[13] B.Suchitha Samuel, J.Mrudula, -Design of Intelligent Solar Tracker Robot for Surveillance,\| International Journal of Advanced Research in Electrical, Electronics and Instrumentation Engineering, Vol. 2, Issue 10, October 2013.

[14] Bhavesh Pandey1, Anita Agrawal, - Automatic Sun Tracking System Using PSoC, II International Journal of Innovative Research in Science, Engineering and Technology, Vol. 1, Issue 1, November 2012.

[15] MazidiMd.Ali, Mazidi J.G.,-The 8051 Microcontroller and Embedded systems\|, Pearson Education, 2nd edition.

[16] Mohamed Sabry "Temperature optimization of high concentrated active cooled solar cells" March 2016 DOI: 10.1016/j.nrjag.2016.03.002

[17] Manxuan Xiao, Llewellyn Tang "A review on recent development of cooling technologies for concentrated photovoltaics systems" November 2018 DOI: 10.3390/en11123416 
[18] Mohamed Sabry, MouaazNahas "Simulation of a Standalone Portable Steam Generator Driven by a Solar Concentrator" May 2015 DOI: $10.3390 /$ en8053867

[19] B.Suchitha Samuel, J.Mrudula, -Design of Intelligent Solar Tracker Robot for Surveillance,l International Journal of Advanced Research in Electrical, Electronics and Instrumentation Engineering, Vol. 2, Issue 10, October 2013.

[20] Meghana Sharma, -An Efficient Low Cost Solar Tracker Using Microcontroller,\| IOSR Journal of Electrical and Electronics Engineering (IOSR-JEEE), Volume 9, Issue 4 Ver. V (Jul - Aug. 2014), PP 37-40.

[21] David Appleyard, "Solar Trackers: Facing the Sun," Renewable Energy World Magazine, UK: Ralph Boon, 2009.

[22] P. Hatfield, "Low cost solar tracker, bachelor of electrical engineering thesis," Department of Electrical and Computer Engineering, Curtin University of Technology 2006

[23] ] K. Sopian, H. T. Liu, S. Kakac, and T. N. Veziroglu, "Performance of a double pass photovoltaic thermal solar collector suitable for solar drying systems," Energy Conversion and Management, vol. 41, no. 4, pp. 353-365, 2000.

[24] J. Prakash, "Transient analysis of a photovoltaic-thermal solar collector for co-generation of electricity and hot air/water," Energy Conversion and Management, vol. 35, no. 11, pp. 967-972, 1994

[25] T. Bergene and O. M. Løvvik, "Model calculations on a flatplate solar heat collector with integrated solar cells," Solar Energy, vol. 55, no. 6, pp. 453-462, 1995.

[26] D. W. de Vries, Design of a photovoltaic/thermal combi-panel [Ph.D. thesis], Eindhoven Technical University, Eindhoven, The Netherlands, 1998.

[27] T. Fujisawa and T. Tani, "Annual exergy evaluation on photovoltaic-thermal hybrid collector," Solar Energy Materials and Solar Cells, vol. 47, no. 1-4, pp. 135-148, 1997.

[28] B. Norton and J. E. J. Edmonds, "Aqueous propylene-glycol concentrations for the freeze protection of thermosyphon solar energy water heaters," Solar Energy, vol. 47, no. 5, pp. 375-382, 1991.

[29] G. Rockendorf, R. Sillmann, L. Podlowski, and B. Litzenburger, "PV-hybrid and thermoelectric collectors," Solar Energy, vol. 67, no. 4-6, pp. 227-237, 1999.

[30] M. W. Davis, A. H. Fanney, and B. P. Dougherty, "Prediction of building integrated photovoltaic cell temperatures," Journal of Solar Energy Engineering, vol. 123, no. 3, pp. 200-210, 2001.

[31] B. Moshfegh and M. Sandberg, "Flow and heat transfer in the air gap behind photovoltaic panels," Renewable and Sustainable Energy Reviews, vol. 2, no. 3, pp. 287-301, 1998.

[32] J. A. Clarke, J. W. Hand, C. M. Johnstone, N. Kelly, and P. A. Strachan, "Photovoltaic-integrated building facades," Renewable Energy, vol. 8, no. 1-4, pp. 475-479, 1996.

[33] B. J. Brinkworth, R. H. Marshall, and Z. Ibarahim, "A validated model of naturally ventilated PV cladding," Solar Energy, vol. 69 , no. 1, pp. 67-81, 2000.

[34] J.C. Hollick, "Solar cogeneration panels," Renewable Energy, vol. 15, no. 1, pp. 195-200, 1998.

[35] A. Akbarzadeh and T. Wadowski, "Heat pipe-based cooling systems for photovoltaic cells under concentrated solar radiation," Applied Thermal Engineering, vol. 16, no. 1, pp. 81-87, 1996

[36] A. Luque, G. Sala, J. C. Arboiro, T. Bruton, D. Cunningham, and N. Mason, "Some results of the EUCLIDES photovoltaic concentrator prototype," Progress in Photovoltaics: Research and Applications, vol. 5, no. 3, pp. 195-212, 1997.

[37] S. Ito, N. Miura, and K. Wang, "Performance of a heat pump using direct expansion solar collectors," Solar Energy, vol. 65, no. 3, pp. 189-196, 1999.

[38] S. Ito and N. Miura, "Photovoitaic and thermal hybrid systems," in Proceedings of the Asia-Pacific Conference of International Solar Energy Society, pp. 73-78, Gwangju, South Korea, October 2004.

[39] P. Affolter, D. Ruoss, P. Toggweiler, and B. A. Haller, "New Generation of Hybrid Solar Collectors," Final Report DIS 56360/16868, Swiss Federal Office for Energy, 2000.
[40] IEA, "Photovoltaic/thermal solar energy systems: status of the technology and roadmap for future development," Task 7 Report, International Energy Agency, PVPS T7-10, 2002.

[41] A. A. Hegazy, "Comparative study of the performances of four photovoltaic/thermal solar air collectors," Energy Conversion and Management, vol. 41, no. 8, pp. 861-881, 2000.

[42] Y. Tripanagnostopoulos, T. Nousia, M. Souliotis, and P. Yianoulis, "Hybrid photovoltaic/thermal solar systems," Solar Energy, vol. 72, no. 3, pp. 217-234, 2002 